\title{
BADANIE WSPÓŁZALEŻNOŚCI RYNKÓW KAPITAŁOWYCH I WALUTOWYCH Z ZASTOSOWANIEM MODELI MGARCH
}

\begin{abstract}
$\mathrm{Z}$ a r y s t r e ś c i. W artykule podjęto próbę zbadania wzajemnych relacji pomiędzy wybranymi indeksami giełdowymi, relacji pomiędzy kursami walut, a następnie określono kierunek przepływu informacji pomiędzy rynkami kapitałowym i walutowym. Do oszacowania współzależności instrumentów inwestycyjnych posłużył wielowymiarowy model klasy GARCH. Praca jest kontynuacją poprzednich badań autora związanych z taksonometryczną klasyfikacją giełd na świecie.
\end{abstract}

S ł o w a k 1 u c z o w e: wielowymiarowy model GARCH, analiza współzależności, giełdy papierów wartościowych, waluty.

\section{WSTĘP}

Badania nad wzajemnym oddziaływaniem rynków kapitałowych i walutowych na świecie trwają już od wielu lat, niemniej temat ten nie stracił na swojej popularności. Szczególnie w ostatnim roku, gdy na skutek gwałtownego wycofania inwestorów z giełdy, napływu kapitału spekulacyjnego oraz licznych bankructw znanych firm, dyskusje o przenikaniu się wpływów poszczególnych giełd na siebie były bardzo gorące. W tym samym czasie dużym zainteresowaniem cieszyły się również wahania na rynku walut. Celem niniejszego referatu jest zbadanie relacji między giełdami papierów wartościowych $\mathrm{z}$ wybranych krajów oraz kursami walut z nimi związanymi. Praca jest kontynuacją wcześniejszych badań autora nad klasyfikacją giełd na świecie, które obecnie będą analizowane pod względem wzajemnego oddziaływania w aspekcie kierunku przepływu informacji. Narzędziami badawczymi zastosowanymi w tym celu są wielowymiarowe modele klasy GARCH (Multivariate GARCH Models). 


\section{METODOLOGIA}

Dysponując mapą podziału giełd wynikającą z poprzednich analiz autora ${ }^{1}$, podjęto próbę określenia, $w$ jakim kierunku przepływają informacje pomiędzy wyodrębnionymi grupami i tym samym zbadania, jaki jest ich wzajemny wpływ oddziaływania. W badaniu posłużono się wielowymiarowym modelem $M G A R C H$, opierając się na dziennych stopach zwrotu z głównych indeksów oraz kursów walutowych. Ponieważ trudnością byłoby przeanalizowanie zmian wszystkich indeksów, zdecydowano się na wybór reprezentantów grup i tak do specyfikacji równan modelu przyjęto logarytmowane stopy zwrotu (1) z indeksów: Nasdaq, Dow Jones, S\&P500, DAX, CAC40, FTSE250, SSE Comp., WIG20, a także kursów walut reprezentujących kraje, z których pochodzą wybrane indeksy. Sa nimi: EUR/USD, EUR/GBP, EUR/PLN, USD/GBP, USD/CNY, CNY/GBP, CNY/PLN, CNY/EUR, GBP/PLN.

Punktem wyjścia analizy są pojęcia warunkowych wartości oczekiwanych, warunkowej macierzy wariancji-kowariancji oraz warunkowego rozkładu standaryzowanych reszt modelu, danego równaniem:

$$
r_{t}=100\left(\ln P_{t}-\ln P_{t-1}\right)=\mu_{t}+\varepsilon_{t}=\mu_{t}+\sqrt{h_{t}} z_{t}
$$

$P_{t}$ - wartość indeksu (kursu) w okresie $t, P_{t-1}$ - wartość indeksu (kursu) w okresie $t-1, \mu_{t}$ - warunkowa wartość oczekiwana stopy zwrotu $r_{t} \mathrm{w}$ chwili $t$ $\left(\mu_{t}=\mathrm{E}\left[r_{t} \mid I_{t-1}\right]\right), \varepsilon_{t}-$ reszta modelu, $h_{t}$ - warunkowa wariancja stopy zwrotu w chwili $t\left(h_{t}=\operatorname{var}\left[r_{t} \mid I_{t-1}\right]\right), z_{t}$ - niezależne reszty modelu o zerowej średniej i jednostkowej wariancji, $I_{t-1}$ - informacja dostępna w chwili $t$.

Więcej informacji metodologicznych na temat modelowania procesów stochastycznych można znaleźć w literaturze (Osińska, 2006; Fiszeder, 2009). W niniejszym referacie skupiono uwagę na najważniejsze kwestie konstrukcji modelu MGARCH.

Chociaż od zaproponowania przez Engle'a i Bollersleva (1986) jednorównaniowych modeli ARCH i GARCH minęło ponad 20 lat, ich podejście do zmiennych w czasie wariancji stóp zwrotu jest wciąż aktualne i rozwijane. Naturalnym rozszerzeniem modeli GARCH na potrzeby analiz rynków finansowych stał się wprowadzony przez Bollersleva (1988) roku model wielowymiarowy MGARCH (Multivariate GARCH). W części empirycznej niniejszej pracy ten właśnie model posłuży do opisania wzajemnego wpływu giełd i kursów walut na świecie.

Ogólna postać modelu wielowymiarowego, która jest odpowiednikiem jednorównaniowego modelu GARCH(1,1) określona w pracy Bollerslev, Engle, Wooldridge (1988) nazwą VECH-GARCH dana jest równaniem:

\footnotetext{
${ }^{1}$ T. Chruściński, Analiza wielowymiarowa giełd papierów wartościowych na świecie, „Wiadomości statystyczne", nr 9, GUS, Warszawa 2008, s. 50-61.
} 


$$
\operatorname{vech}\left(\mathbf{H}_{\tau}\right)=\operatorname{vech}(\mathbf{W})+\mathbf{A} \operatorname{vech}\left(\varepsilon_{t-1}^{T} \cdot \varepsilon_{t-1}\right)+\mathbf{B} \operatorname{vech}\left(\mathbf{H}_{\mathbf{t}-\mathbf{1}}\right),
$$

gdzie operator vech(.) jest operatorem wektoryzacji symetrycznej.

Aby estymacja modelu (2) była poprawnie przeprowadzona, konieczne jest spełnienie szeregu warunków. Należy zapewnić dodatnią określoność i stacjonarność macierzy $\mathbf{H}_{t}$ dla każdej chwili $t$, co wymaga dodatniej określoności macierzy A oraz $\mathbf{B}$ i jest związane z wprowadzeniem bardzo skomplikowanych nieliniowych warunków ograniczających. Podstawową konsekwencją pełnej postaci równania VECH jest konieczność oszacowania dużej liczby parametrów, która już w modelu dwuwymiarowym wynosi 21 . Problemy te powoduja, że model znalazł małe zastosowanie w praktyce. Rozwiązaniem okazały się modele z diagonalnymi macierzami A i B, które zredukowały liczbę szacowanych parametrów i wyeliminowały tzw. efekt przenikania wariancji poprzez uzależnienie elementów macierzy $\mathbf{H}_{t}$ od swoich przeszłych wartości $h_{i j, t}$ oraz iloczynów błędów z chwili $t\left(\varepsilon_{i, t} \varepsilon_{j, t}\right)$. Ogólna postać diagonalnego modelu VECH (DVECH) jest następująca:

$$
\mathbf{H}_{\mathbf{t}}=\mathbf{W}+\overline{\mathbf{A}} \circ\left(\varepsilon_{t-1}^{T} \varepsilon_{t-1}\right)+\overline{\mathbf{B}} \circ \mathbf{H}_{\mathbf{t}}
$$

gdzie: $\overline{\mathbf{A}}=\operatorname{ivech}(\operatorname{diag}(\mathbf{A})), \overline{\mathbf{B}}=\operatorname{ivech}(\operatorname{diag}(\mathbf{B}))$, iloczyn $X \circ Y$ to iloczyn Hadamarda, a ivech $(\cdot)$ jest operatorem odwrotnym do vech(.).

Po sprowadzeniu macierzy A i B do ich postaci diagonalnych, otrzymujemy ostateczną postać modelu DVECH, która jest rozszerzeniem modelu GARCH(1,1) (por. Yang, 2001).

Szczególną odmianą modelu VECH jest model BEKK, który w prosty sposób rozwiązuje problem braku dodatniej macierzy kowariancji. Ponieważ jednak trudno jest uzyskać stacjonarność macierzy $\mathbf{H}_{t}$ oraz małą liczbę szacowanych parametrów (por. Piontek, 2006), podobnie stosuje się diagonalne macierze A i B uzyskując model DBEKK(2)

$$
\mathbf{H}_{\mathbf{t}}=\mathbf{W}^{\mathrm{T}} \mathbf{W}+\mathbf{A}^{\mathrm{T}} \varepsilon_{t-1} \varepsilon_{t-1} \mathbf{A}+\mathbf{B}^{\mathrm{T}} \mathbf{H}_{\mathbf{t}-\mathbf{1}} \mathbf{B} .
$$

Dzięki zastosowaniu postaci diagonalnych można zastosować estymację każdego z równań modeli (3) i (4) osobno, unikając w ten sposób szeregu problemów optymalizacyjnych metody największej wiarygodności dla kilku równań jednocześnie. $\mathrm{W}$ przykładzie empirycznym zastosowano maksymalizację funkcji największej wiarygodności określoną wzorem:

$$
L L F=-\frac{1}{2} \sum_{t=1}^{T}\left[\ln \left|\mathbf{H}_{\mathbf{t}}\right|+\varepsilon_{t}^{\prime} \mathbf{H}_{\mathbf{t}}^{-1} \varepsilon_{t}\right]
$$




\section{WYNIKI EMPIRYCZNE}

Do badania wykorzystano dzienne stopy zwrotu na głównych indeksach giełdowych z wybranych krajów oraz związanych z nimi kursów walutowych. Szeregi czasowe dostosowano do porównywalności poprzez usunięcie stóp zwrotu dla okresów, w których brakowało danych choćby jednej zmiennej. Ostatecznie otrzymano 1865 obserwacji z okresu od stycznia 2001 roku do kwietnia 2009 roku. Dla tak przygotowanych danych zbudowano modele klasy diagonal VECH, diagonal BEKK oraz dla porównania model stałej korelacji warunkowej CCC w celu oceny, który z nich będzie najlepiej dopasowany do rzeczywistości. Po oszacowaniu kilkudziesięciu modeli zdecydowano na wykorzystanie warunkowego rozkładu t-Studenta, który dał lepsze rezultaty oszacowań parametrów niż rozkład normalny.

Tabela 1. Porównanie przykładowych wyników estymacji modeli według kryterium AIC

\begin{tabular}{|c|c|c|c|c|}
\hline \multirow{2}{*}{ Model } & \multicolumn{3}{|c|}{ Wartości kryterium AIC } & \multirow{2}{*}{$\begin{array}{l}\text { Optymalny } \\
\text { model }\end{array}$} \\
\hline & DVECH & $\mathrm{CCC}$ & DBEKK & \\
\hline 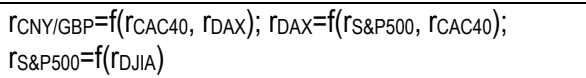 & $-19,67690$ & $-19,59901$ & $-19,65051$ & DVECH \\
\hline $\begin{array}{l}r_{C N Y / P L N}=f\left(r_{D J I A}, r_{C A C 40}\right) ; r_{C A C 40}=f\left(r_{S \& P 500,} r_{D A X}\right) ; \\
r_{D A X}=f\left(r_{N A S D A Q}\right)\end{array}$ & $-20,14000$ & $-20,03808$ & $-20,12827$ & DVECH \\
\hline $\begin{array}{l}r_{C N Y I E U R}=f\left(r_{D J I A}, r_{W I G 20}\right) ; r_{C A C 40}=f\left(r_{S \& P 500}, r_{D A X}\right) ; \\
r_{\text {WIG20 }}=f\left(r_{F T S E 250,} r_{D A X}\right)\end{array}$ & $-18,85461$ & $-18,79951$ & $-18,84235$ & DVECH \\
\hline 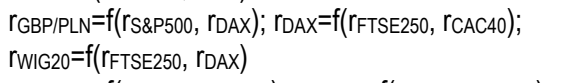 & $-18,56941$ & $-18,55939$ & $-18,54189$ & DVECH \\
\hline $\begin{array}{l}r_{E U R / P L N}=f\left(r_{S \& P 500}, r_{C A C 40}\right) ; r_{S \& P 500}=f\left(r_{N A S D A Q}, r_{D J I A}\right) ; \\
r_{C A C 40}=f\left(r_{S \& P 500}, r_{D A X}\right)\end{array}$ & $-20,02900$ & $-20,02989$ & $-19,99533$ & CCC \\
\hline $\begin{array}{l}r_{W I G 20}=f\left(r_{N A S D A Q}, r_{D A X}\right) ; r_{D A X}=f\left(r_{S \& P 500,} r_{C A C 40}\right) ; \\
r_{S \& P 500}=f\left(r_{D J I A}\right)\end{array}$ & $-18,12994$ & $-18,13056$ & $-18,10009$ & CCC \\
\hline $\begin{array}{l}\text { rWIG20 }=f\left(r_{S \& P 500}, r_{D A X}\right) ; r_{D A X}=f\left(r_{S \& P 500,} r_{C A C 40}\right) ; \\
\text { rS\&P00 }=f\left(r_{D J I A}\right)\end{array}$ & $-18,13948$ & $-18,14146$ & $-18,11020$ & $\mathrm{CCC}$ \\
\hline $\begin{array}{l}\text { rWIG20 }=f\left(r_{D J I A}, r_{D A X}\right) ; r_{D A X}=f\left(r_{S \& P 500,} r_{C A C 40}\right) \\
r_{D J J A}=f\left(r_{S \& P 500}\right)\end{array}$ & $-18,17052$ & $-18,17640$ & $-18,14694$ & $\mathrm{CCC}$ \\
\hline $\begin{array}{l}r_{W I G 20}=f\left(r_{\text {NASDAQ}}, r_{F T S E 250}\right) ; r_{F T S E 250}=f\left(r_{S \& P 500}, r_{C A C 40}\right) ; \\
r_{C A C 40}=f\left(r_{S \& P 500}, r_{D A X}\right)\end{array}$ & $-19,08696$ & $-19,08302$ & $-19,06386$ & DVECH \\
\hline $\begin{array}{l}r_{W I G 20}=f\left(r_{S \& P 500}, r_{F T S E 250}\right) ; r_{F T S E 250}=f\left(r_{S \& P 500}, r_{C A C 40}\right) \\
r_{S \& P 500}=f\left(r_{D J I A}\right)\end{array}$ & $-18,81325$ & $-18,83295$ & $-18,77934$ & CCC \\
\hline $\begin{array}{l}\text { rWIG20=f(rDJA, rFTSE250); rFTSE250=f(rS\&P500, rCAC40); } \\
\text { rDJIA }=f(\text { rs\&P500) }\end{array}$ & $-18,86222$ & $-18,88397$ & $-18,83241$ & CCC \\
\hline $\begin{array}{l}r_{S S E}=f\left(r_{F T S E 250}\right) ; r_{F T S E 250}=f\left(r_{S \& P 500}\right) \\
r_{S \& P 500}=f\left(r_{\text {NASDAQ }}, r_{D J I A}\right)\end{array}$ & $-18,50009$ & $-18,51034$ & $-18,44585$ & $\mathrm{CCC}$ \\
\hline $\begin{array}{l}r_{S S E}=f\left(r_{\text {FTSE250 }}\right) ; r_{\text {FTSE250 }}=f\left(r_{S \& P 500,} r_{C A C 40}\right) ; \\
r_{\text {WIG } 20}=f\left(r_{S \& P 500}, r_{D A X}\right)\end{array}$ & $-17,77209$ & $-17,77804$ & $-17,72810$ & CCC \\
\hline
\end{tabular}

Źródło: obliczenia własne w programie EViews 6.0.

Celem badania było określenie kierunku wpływu giełdy reprezentującej jedną grupę na reprezentanta innej, wzajemnego wpływu na siebie kursów wa- 
lutowych i w konsekwencji zbadanie zależności pomiędzy rynkiem giełdowym i walutowym. Mając do dyspozycji stopy zwrotu z 8 indeksów oraz 9 kursów walutowych analizie poddano kilkaset wielowymiarowych kombinacji. $Z$ uwagi na ograniczony rozmiar publikacji zdecydowano się na zaprezentowanie Tylko przykładowych wyników oszacowanych modeli. Kryterium wyboru była wartość AIC. Wyniki porównań przedstawia tabela 1.

Analizując zaprezentowane w tabeli 1 . wyniki estymacji, zauważalne jest, że najlepszymi do badania wzajemnego oddziaływania indeksów giełdowych i kursów walutowych są diagonalny model VECH oraz model stałej korelacji warunkowej CCC. Ta sama struktura optymalnych modeli występuje dla wszystkich wyników badania współzależności. Przykładowy empiryczny wielorównaniowy model DVECH przedstawiony został poniżej:

$$
\begin{aligned}
& r_{\text {EUR/PLN }(t)}=-0,000332-0,042826 \cdot r_{S \& P 500(t-1)}+0,024953 \cdot r_{C A C 40(t-1)}+\varepsilon_{t} \\
& r_{S \& P 500(t)}=0,000576+0,016579 \cdot r_{\text {NASDAQ(t-1) }}-0,093922 \cdot r_{\text {DJA(t-1) }}+\varepsilon_{t} \\
& r_{\text {CAC40(t) }}=0,0007+0,420494 \cdot r_{S \& P 500(t-1)}-0,20429 \cdot r_{\text {DAX }(t-1)}+\varepsilon_{t}
\end{aligned}
$$

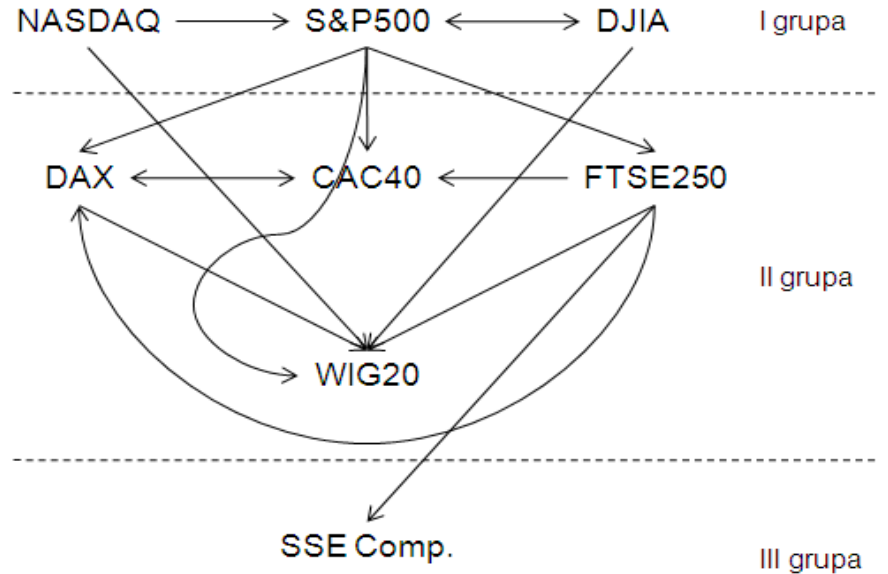

Rysunek 1. Wzajemny wpływ giełd papierów wartościowych reprezentowany przez główne indeksy w okresie od stycznia 2001 do kwietnia 2009 roku

Źródło: opracowanie własne.

Ciekawszą stroną wyników obliczeń jest interpretacja ekonomiczna zbudowanych modeli wielowymiarowych. Na podstawie poprawnie oszacowanych zmiennych objaśniających poszczególnych równań wyraźnie widoczny jest kierunek przepływu informacji z poprzedniego dnia pomiędzy poszczególnymi giełdami. Ilustrację wzajemnego wpływu giełd papierów wartościowych wykorzystanych $\mathrm{w}$ badaniu przedstawia rysunek 1 , natomiast rysunek 2 prezentuje wyniki badań przy zastosowaniu analogicznych zmiennych z okresu od stycznia 2001 do września 2008 roku. Porównanie obu rysunków daje wyraźny obraz 
zmian w zależnościach między giełdami w okresie 7 miesięcy okresu kryzysu ekonomicznego.

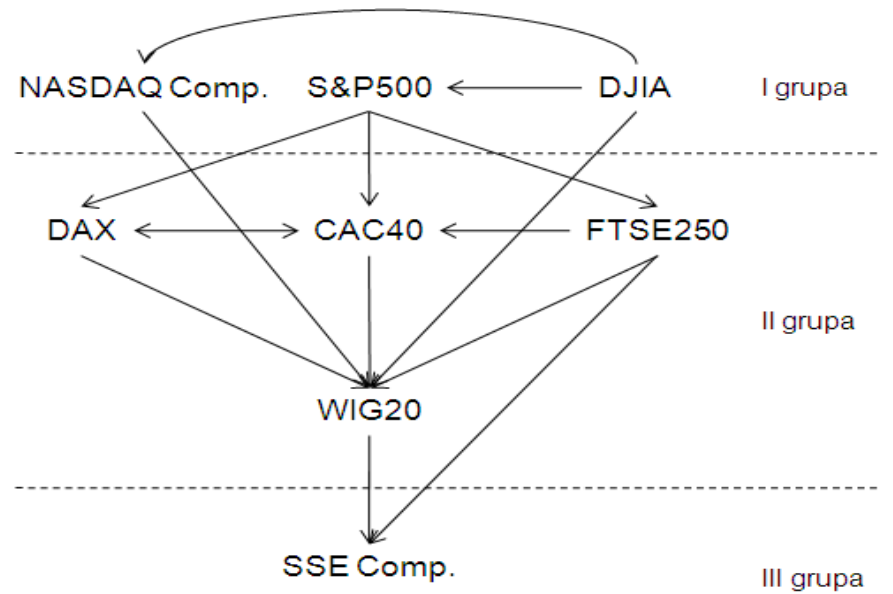

Rysunek 2. Wzajemny wpływ giełd papierów wartościowych reprezentowany przez główne indeksy w okresie od stycznia 2001 do września 2008 roku

Źródło: opracowanie własne na podstawie obliczeń w Chruściński (2009).

Porównując wyniki analiz zamieszczone na rysunkach 1 i 2 , zauważalna jest zmiana kierunku przepływu informacji pomiędzy badanymi giełdami, która nastapiła w okresie od października 2008 roku do kwietnia 2009 roku. Na rynku amerykańskim nie ma już bezpośredniego powiązania indeksów DJIA oraz NASDAQ, z kolei na rynku europejskim londyński indeks FTSE250 zdobył bezpośredni wpływ na niemiecki indeks DAX. Obie giełdy (brytyjska i niemiecka) uczestniczą w kształtowaniu się polskiego indeksu WIG20. Parkiet francuski, który wcześniej pośredniczył w przekazywaniu na polski rynek informacji zawartych $\mathrm{w}$ indeksie S\&P500 nie spełnia już tej funkcji i obecnie „wczorajsze” zmiany amerykańskiego S\&P500 bezpośrednio wpływają na WIG20. Giełda warszawska natomiast straciła swój udział, który wcześniej współdzieliła z giełdą londyńską, w kształtowaniu kursów giełdowych w Szanghaju.

Chcąc zbadać wzajemny wpływ rynków giełdowych i walutowych, warto znać zależności wewnątrzrynkowe. Podobnie jak w przypadku powiązań giełdowych wyznaczono zależności stóp zwrotu na kursach walut powiązanych z krajami, z których pochodzą badane giełdy. Zależności poszczególnych kursów prezentuje rysunek 3 . 


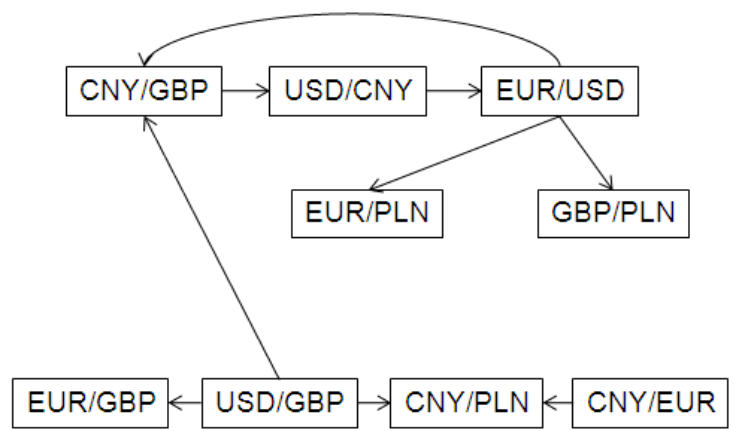

Rysunek 3. Wzajemny wpływ kursów walutowych powiązanych z krajami, z których pochodzą badane giełdy

Źródło: opracowanie własne.

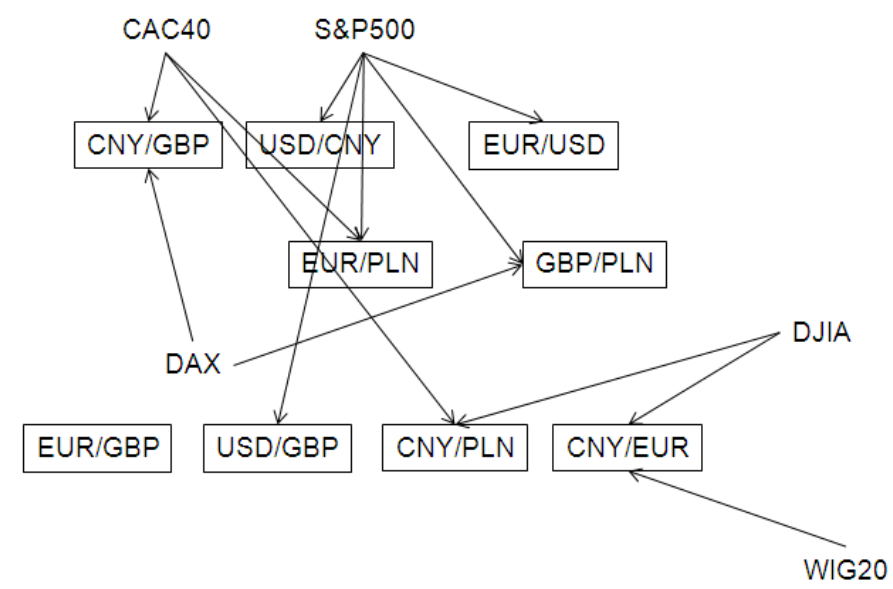

Rysunek 4. Wzajemny wpływ indeksów giełdowych i kursów walutowych powiązanych z krajami, z których pochodzą badane giełdy

Źródło: opracowanie własne.

Przeprowadzona analiza pozwoliła na określenie kierunku oddziaływania na siebie wybranych giełd papierów wartościowych i kursów walutowych. Wyniki tych oddziaływań przedstawia rysunek 4 .

Badanie potwierdziło intuicyjne przypuszczenie na temat współzależności giełd i kursów walutowych. W większej liczbie przypadków kursy walut zależą od zmian indeksów, a nie odwrotnie, co wynika bezpośrednio ze skłonności inwestorów do generowania zysków. W przypadku, gdy na parkiecie dominuje podaż i kursy spółek zniżkują gracze wycofują swój kapitał, pogłębiając malejący trend i inwestują go w zagraniczną walutę. Stąd zwykle zmiany indeksów giełdowych i kursów walut są ze sobą skorelowane ujemnie.

Największy wpływ na kształtowanie się kursów walut w wybranej grupie giełd mają indeksy S\&P500 oraz CAC40. Ich łączny wpływ kształtuje m.in. 
kurs EUR/PLN. Kurs CNY/PLN zależny jest z kolei od indeksu DJIA oraz CAC40. Wynika to $\mathrm{z}$ faktu, że amerykańska gospodarka ściśle współpracuje z gospodarką chińską i ma silny wpływ na juana. Z punktu widzenia polskiej giełdy interesujące jest, że indeks WIG20 ma wpływ na kurs CNY/EUR. Ta zależność może wynikać z nieodległego w czasie wpływu warszawskiego parkietu przy współudziale londyńskiego na indeks giełdy szanghajskiej. Powiązanie giełdy SSE w tym zestawieniu zależności jest wówczas bardzo naturalne.

W niniejszym badaniu jedynie kurs EUR/GBP okazał się niezależny od jakiejkolwiek analizowanej giełdy. Na jego kształtowanie ma natomiast wpływ kurs USD/GBP. Zaprezentowane w niniejszej pracy wyniki analiz mają charakter fragmentaryczny dla badań nad współzależnością rynków kapitałowych i walutowych. Z uwagi na czasochłonność i złożoność obliczeń zamieszczone zestawienia modeli i analiz pełnią funkcję poglądową i przedstawiają przykład zastosowania modeli MGARCH.

\section{LITERATURA}

Bollerslev T., Engle, R., Wooldridge, J. (1988), A Capital Asset Pricing Model with Time-Varying Covariance, ,Journal of Political Economy”, University of Chicago Press, vol. 96(1).

Bollerslev T. (1986), Generalized Autoregressive Conditional Heteroskedasticity, „Journal of Econometrics”, 31, 307-327.

Chruściński T. (2008), Analiza wielowymiarowa giełd papierów wartościowych na świecie, „Wiadomości statystyczne”, nr 9, 50-61.

Chruściński T. (2009), Wykorzystanie wielowymiarowych modeli klasy GARCH do badania wzajemnego wptywu rynków finansowych na świecie, „Equilibrium”, Wydawnictwo Naukowe UMK, Toruń, nr 1(2), 61-68.

Engle R. (1982), Autoregressive Conditional Heteroskedasticity with Estimates of the Variance of UK Inflation, „Econometrica”, 50, 987-1008.

Fiszeder P., (2009), Modele klasy GARCH w empirycznych badaniach finansowych, Wydawnictwo UMK, Toruń.

Osińska M. (2006), Ekonometria finansowa, PWE, Warszawa.

Piontek K. (2006), Wyzwania praktyczne $w$ modelowaniu wielowymiarowych procesów GARCH, ,Taksonomia”, Akademia Ekonomiczna, Wrocław, nr 13.

Yang W. (2001), M-GARCH Hedge Ratios and Hedging Effectiveness in Australian Futures Markets, Edith Cowan University. 


\section{THE RESEARCH OF INTERDEPENDENCE ON CAPITAL AND CURRENCY MARKETS USING MULTIVARIATE GARCH MODELS}

$\mathrm{A} \mathrm{b} \mathrm{s} \mathrm{t} \mathrm{r} \mathrm{a} \mathrm{c} \mathrm{t.} \mathrm{In} \mathrm{the} \mathrm{article} \mathrm{an} \mathrm{attempt} \mathrm{was} \mathrm{made} \mathrm{to} \mathrm{investigate} \mathrm{the} \mathrm{interaction} \mathrm{among} \mathrm{the} \mathrm{various}$ stock exchanges as well as various currency rates and then to define the direction of information flow between capital and currency markets. Tools used in this study are Multivariate GARCH models. Present work is a continuation of an earlier study of World Stock Exchange classification. These stock exchanges will be further analyzed according to their interaction.

K e y w o r d s: Multivariate GARCH Model, independence analysis, Stock Exchanges, currency. 
